\title{
Towards Complementarity and Curricular Improvements of the Courses on Strategies for Personal Development, Freshmen Orientation Seminar, and Understanding the Self
}

\author{
Amor Mia Arandia ${ }^{1}$, Melfi Caranto ${ }^{2}$, Reynold Padagas, ${ }^{3, *}$ \\ ${ }^{1}$ Department of Psychology, College of Liberal Arts, Criminology and Education, Jose Rizal University, Philippines \\ ${ }^{2}$ College of Liberal Arts, Criminology and Education, Jose Rizal University, Philippines \\ ${ }^{3}$ College of Liberal Arts, Criminology and Education; College of Nursing and Health Sciences, Jose Rizal University, Philippines
}

Received April 7, 2020; Revised April 29, 2020; Accepted June 16, 2020

Copyright $@ 2020$ by authors, all rights reserved. Authors agree that this article remains permanently open access under the terms of the Creative Commons Attribution License 4.0 International License

\begin{abstract}
Delivering quality instruction is fundamental in any educational institution and, this calls for a teacher sense of responsibility. Teachers create their instructional designs for specific courses and ensure that resources are available to achieve learning objectives. However, some instructional designs of several courses appear to be containing similar components, including contents; hence, this study evaluated three courses. These courses include Understanding the Self (UTS C101), a new general education subject in college is believed to be overlapping in terms of content with Strategies for Personality Development (PD), a course in Senior High School (SHS) and Freshmen Orientation Seminar (FOS 101), a unique course taken by freshmen college students in a private university in the Philippines. Since the courses are reputed to be related and presumed intertwined in terms of curricular content, the researchers embarked on a comparative-document analysis using the syllabus containing lessons, teaching methodologies, and student assessment methods. The findings showed an array of similarities and differences of lessons taught, learning activities, student learning assessment strategies, and other pedagogical methods used. The results have direct implications for the University to be able to foster curricular improvements and ensure complementarity between and among the three courses explored. This is also in response to the challenges brought by outcomes-based education, which was newly integrated as an educational framework in the University. A policy recommendation for the University was initiated based on the results of this study.
\end{abstract}

Keywords Curriculum, Freshmen Orientation Seminar, General Education, Personality Development,
Understanding the Self

\section{Introduction}

The introduction of an additional two years in high school, popularly known as senior high school, created obvious tons of challenges in the tertiary curriculum. The new General Education (GE) courses, alongside the course on Rizal's Life and Works based on RA No. 1425, were recently mandated by the Commission on Higher Education (CHED) through CHED Memorandum Order (CMO) No. 20, Series of 2013.

With this, challenging situations keep on rubbing people who are directly concerned in the attainment of learning outcomes for the courses - the teachers and students.

While many educators are compelled to implement changes in curriculum and provide additional subjects mandated to be taught, it is crucial to carefully examine the creation of these courses as well as its implementation. After all, the goal of HEI's is to assure high-quality education in all subject matters and that standard of instruction and learning are kept (Fink, 2011, p. 1). It is of high importance to bear that any change in institutional structure in high school may impact additions or changes in college courses or its mode of delivery.

Furthermore, educational stakeholders, especially in private universities that offer both high school and college, need to ensure that lessons taught from one level to another are created in upward and in deepening levels that will help students achieve not only foundational literacy 
but obtain competencies which will prepare them in life and in their profession. It is the responsibility of educators whom both have influence in high school and college levels to examine courses or its curriculum content to maintain high standards in education as the students move up from one level to another.

The syllabus is a fundamental educational tool that presents a framework of learning to the students. It provides direction and expectations for students and teachers for a particular course (Hess \& Whittington, 2003, p. 23). Considering that a course begins with a syllabus, this research project explored the overlap and complement, of course, that are highly related. The research was designed to point possible improvements in the curricula through the syllabus so that the University's thrust in providing and maintaining high standards of education remains in check to courses that are highly connected and related to each other from one educational level to another.

The findings pose challenges to the academic institution for policy improvements in terms of curricula and the creation of syllabus. Through these policy improvements, the delivery of instruction in course subjects that are highly related will be geared toward quality student learning and in the OBE-oriented framework.

\subsection{Background of the Study}

The study took place in a private university in the Philippines. The University newly implemented the Strategies for Personality Development (PD) as a course for senior high school. In college, Understanding the Self (UTS C101) was instituted. The Understanding the Self (UTS C101), is believed to be overlapping in terms of content with Strategies for Personality Development (PD), and Freshmen Orientation Seminar (FOS 101), a unique course taken by freshmen college students in Jose Rizal University (JRU).

The Personality Development course aims to help the senior high school students cope with the middle and late adolescence stage of their growth and development that specifically deals with the psychological as well as social aspects of their well being. The said course aims to take an in-depth analysis of the developmental changes in their set of skills and traits that can help them analyze and arrive at a decision in this stage of their life. This course also intends to learn some techniques and strategies in coping with situations that will challenge their psychological and strategic abilities. This course may also help the students analyze their relationship with family, friends, and significant others and its influence in their decision making. Finally, the course shall help them reflect on the career path that they want to achieve later in life.

Meanwhile, the Freshmen Orientation Seminar (FOS C101) 11, also known as the Strategies for Academic
Success in College, is a 3-unit course. This is taken by first-year college students during the first semester of the academic year. FOS C101 introduces college students to college-level thinking skills, interpersonal skills, and practical study skills necessary for success in college.

Furthermore, the purpose of this course is to assist entering first-year students in adjusting to college life and to enhance their knowledge of Jose Rizal University. Significant topics include goal setting, time management, efficient and critical reading, note-taking, concentration and memory development, study techniques, test-taking, vocabulary development, and other skills needed in successful transitions associated with college life. The course provides blended learning. At the end of FOS C101, students are expected to explain the different academic policies of the institution and utilize the various support services and resources of the University. It also aims to helps students show the ability to cope with different present and future classroom tasks in different courses in the curriculum to succeed in college. Moreover, it helps students to demonstrate the ability to use thinking and communication skills on the appreciation of future tasks in different courses in the curriculum to experience academic success in college.

Conversely, the Understanding The Self course intends to facilitate the exploration of the issues and concerns regarding self and identity to arrive at a better understanding of one's self. It strives to meet its goal by stressing the integration of the personal with the academic. Another aim is to help students contextualize matters discussed in the classroom and the everyday experiences of students. The course also aims to make the experiences for better learning, generating a new appreciation for the learning process, and developing a more critical and reflective attitude while enabling them to manage and improve their selves to attain a better quality of life. Significant topics include different aspects of the self, such as philosophical, cognitive, psychological, social, physical, material, sexual, spiritual, political, and managing the self.

Without a doubt, the PD, FOS C101 and UTS C101 as independent courses enrich both the academic and bio-psycho-social developments of students. Since the courses are reputed to be related and are presumed intertwined in terms of curricular content, the researchers embarked on a comparative analysis of syllabic content. We used the syllabus as a point of comparison since it is an essential pedagogical tool which appears to be a map and overview of the course, providing needed information for enhanced student experience. The syllabus is also a learning-focused document designed to communicate clearly and compellingly what the students will gain from the course, what they will do, and how best to get there. It also helps articulate the learning environment in which students can participate.

Likewise, through the syllabus, the teachers are guided 
throughout the semester in terms of the topics, content, learning approaches, and assessment methods used, which not only promotes learning but facilitates the learning experience of students (Lang, 2015, p. 1). Considering that PD, FOS C101 and UTS C101 as general education courses that help prepare the students for holistic development, the syllabi need to be analyzed whether they are aligned and structured attaining the goal of the University in developing their students.

On a broader view, the upgrade and update of curriculum target the development of students by not only acquiring foundational literacy but obtaining competencies which helps them become well-educated and innovative Filipinos in the future with improved quality of life in the country (National Economic Development Authority, 2016). All in all, this sets the stage for higher educational institutions to be proactive in the upgrade and update of curriculum and its delivery, especially in courses like PD, UTS C101, FOS C101, which targets the holistic development of students.

The results of this study shall benefit both the SHS and college as educational institutions to create complementary enhancements in their curricula and instructional designs for PD, FOS C101 and UTS C101. Specifically, the study sought to 1 ) review the content of the three courses and be able to differentiate similarities and dissimilarities; 2) determine the pedagogical content knowledge (PCK) of the teachers teaching the three courses in terms of their strategies, methodologies, and methods of student assessments; and; 3) improve the instructional designs utilizing the outcomes-based education (OBE) framework.

\section{Materials and Methods}

\subsection{Research Design}

The study used a descriptive-qualitative research design based on an inductive method. The inductive method involves exploration of the data by identifying recurring themes, patterns, or concepts and then describing and interpreting observed categories (Nassaji, 2015, p. 130). The researchers also observed and examined the data to find relevant themes and ideas and then, compare and evaluate them. Document analysis was done in which documents are interpreted by the researcher to give voice and meaning around an assessment topic (Bowen, 2009, p. 27).

\subsection{Research Instrument}

The course syllabi and course outlines of Personality Development, Freshmen Orientation Seminar, and Understanding the Self for AY 2018-2019 were the subjects for document analysis. The course syllabi contain the outline of course learning outcomes, teaching and learning strategies, topical content, and assessment methods of the abovementioned courses.

\subsection{Data Gathering Procedure}

The investigators sought the permission of the department heads and deans to conduct the study. They were informed of the purpose, process, and study duration.

\subsection{Treatment of Data}

Document analysis was made to the PD, FOS C101 and UTS C101 instructional designs or syllabi in which the researchers interpreted the syllabus and course content of the subjects. Analysis of documents integrates coding content into categorized themes related to the central question of research (Bowen, 2009, p. 32). Any discrepancies were discussed and resolved.

The researchers had designated timeframe to analyze the documents separately and then had to convene to finalize the findings of the documents that were analyzed. Then, cross-validation and checking of the document analysis were done by each researcher to the course subjects of FOS, PD, and UTS. The researchers corroborated findings across data sets to reduce the impact of potential bias by examining information collected separately. The researchers used the detailed planning process, as suggested by O'Leary (2014). These processes are 1.) creating a list of texts to explore; 2.) considering how texts will be accessed with attention to linguistic or cultural barriers; 3.) Acknowledge and address biases; 4.) develop appropriate skills for research; 5.) consider strategies for ensuring credibility; 6.) knowing the data one is searching for; 7.) considering ethical issues and; 8.) having a back-up plan.

\subsection{Ethical Considerations}

Informed consent was given to the department heads and deans who gave permission to this study. Anonymity and confidentiality were ensured. This research project was funded by the research division of the private University. The documents used in the analysis were kept safe during the study. The researchers sought to adhere to University rules and guidelines on research during the course of this study. The results of the study were communicated to the different departments concerned and respective Deans/Principals of the teachers. The records and data collected will only be stored for about five years.

\section{Results and Discussions}

The researchers conducted a document analysis that focused on doing cross-analysis of the course learning outcomes, teaching strategies, learning strategies and 
evaluation, and assessment of the course subjects, namely, Personality Development, Understanding the Self and Strategies for Academic Success in College. The results are presented below.

\subsection{Course Learning Outcome Contents of PD, UTS C101, and FOS C101}

Course learning outcomes are essential to student learning. These provide the goal and purposes of the courses so that students and teachers are aware of the importance of the course, its lessons, and whether or not the outcomes targeted have been attained or not at the end of the semester.

1. Development of the Person. In the Preliminary Period, analysis of course learning outcomes one between PD and UTS C101 appears to have some similarities. While PD focuses on understanding aspects of the self and self-discovery mostly focused on challenges and stress of middle and late adolescence, the UTS C101 as a course aims to help the students develop a critical and reflective understanding of their self and identity development. PD focused on the period of adolescents in general, while UTS C101 focused on broader and segmented aspects, specifically targeting the theory of the self from different perspectives. It helps the students gain a broader perspective of the different individual "self" aspects that they need to develop to become fully functioning persons.

2. Academic Success. FOSC101, course learning outcomes focused on the orientation and familiarization of the students in student life in JRU and institutional services, support, and academic policies.

A review of course learning outcomes for the midterm period shows differences in the focus of the three courses.

3. Valuing \& Maintaining Healthy Relationships. Document analysis of course learning outcomes 2 in the midterm period shows that PD focuses on helping the students hone and maintain healthy relationships by developing the skills related to it.

4. Examining Environmental/Influential Factors to Self-Development. UTS C101 give emphasis on helping the student see the impact of different forces and institutions that affect his self-concept and identity building.

5. Adaptation to College Education. FOS C101 is more concentrated on developing a student's ability to cope with academic tasks and thereby achieve success in college.

A closer look at these courses shows that PD and UTS C101 learning outcomes are different but seems to be spirally connected. PD appears to be focused on social relationships and is limited, while UTS C101 is geared towards environmental impacts and forces that help define the self. PD's CLO2 appears to be a springboard of UTS C101 CLO2, indicating that there is a spiral connection of learning outcomes.
Document analysis of course learning outcomes for the Final Period for the courses of PD, UTS C101, and FOS C101 illustrate differences of focus.

6. Career Development. PD's focus is on career development and understanding the personal components related to it.

7. Managing and Caring for the Self. UTS C101 is more geared towards the acquisition of skills and learning for more significant and better functionality and quality of life.

8. Developing Thinking and Communication Skills. FOS C101 is more inclined to develop the communication skills of students in handling academic success.

In essence, the course learning outcomes in PD involves the life goals of a student, which is also a topic involved in the UTS C101 discussion. As such, in terms of life goals, the two courses seem to be teaching similar related concepts to the students. Thus, in terms of CLO3, there is no indication of higher or increasing knowledge in these course learning outcomes. FOS C101 CLO3 appears to be completely different and unrelated to PD's and UTS C101 course learning outcomes.

\subsection{Course Content of PD, UTS C101, and FOS C101}

The course content reflects the various topics which are focused during discussions and learning sessions in the classroom. Comparison of course content presents the commonality, overlapping, and differences of subjects taught. Findings for the preliminary period content across the three courses are presented in here.

9. The Student in the University. FOS C101, as a subject in the Prelim, emphasized the roles and responsibilities of the student, orientation of the University, its rules and regulation, policies, and guidelines. These topics help the student understand the expectation and conduct asked of them while inside the University.

10. Perspectives of Self Development. PD and UTS C101 as subjects appear to be very different from FOS C101 in the Preliminary Period. PD and UTS C101 appear to begin their prelims with an array of discussion points on aspects of oneself and its development.

10.1 Development \& Challenges of the Self. PD focused their topics in the Adolescent period, particularly discussing Freud's psychosexual stages and Erikson's psychosocial stages of development. These topics included theories of development knowing oneself, developing the whole person, developmental stages in middle and late adolescence, challenges of middle and late adolescence with more emphasis on the growth and development of students experiencing middle and late adolescents. The concept of knowing oneself and the whole person is discussed in a general perspective on PD.

10.2 Psychological \& Social View of the Self. UTSC101 also mentioned Freud's Personality 
Development and Erikson's Psychosocial Stages. However, it expanded the lessons to more psychological concepts Thinking Self, Feeling Self, Basic Emotions and the Interconnection of Emotions, Thoughts, Sensations, and Behavior, the self as a cognitive construct, the self, society and culture, and gender and self are topics helping the student in "knowing oneself" but in a more holistic manner. UTS C101 tackled issues and concerns beyond an adolescent stage. Despite tackling similar topics, a comparison between the abovementioned two subjects shows that UTS C101, under the topic of psychological self and social view of self, has expanded its emphasis, which includes all other life stages development from birth to old age. The topic of social self focuses on increasing students' awareness of other agents that impact his or her development.

Since the two courses, UTS C101 and PD, discussed Freud and Erik Erikson's adolescent theory of development, these points out similarities of content, which may put a question in how these topics are deepened and understood more in different educational levels.

It prepares college student to contemplate life beyond adolescent years until old age.

11. Physical Development. PD also discusses the physical self of the adolescent under the topics "challenges of the middle adolescent". UTS C101 also discusses the Physical and Sexual self of the adolescent/college period but expands the lessons including human sexual behavior, sexual diseases and problems. This increases sexual education for students. Discussions on this area of the self appear to be more extensive for UTS C101 while only the basic knowledge is touched in PD. PD also discusses some philosophers or pioneers in the field of adolescent development, which is also discussed in UTS C101. Overall, some of these observations through the document analysis of syllabus course content in PD and UTS C101 show a repetition of topics.

12. Promoting Mental Well-Being. For the midterm period content lesson, all three courses mentions topic related to the promotion of mental well-being. PD and UTS topics centers on emotional well-being, both discussing coping with stress. On the other hand, FOS C101 discusses ways to cope with first year of college. FOS C101 focus is more on helping students cope with their test anxiety and stage presentation fears. PD and UTS once again have similar topics which approaches it in different angles although not indicating higher levels of learning or spiral increase of knowledge.

13. Thinking and Learning Strategies. In terms of academic success in college, FOS C101 discusses how to improve students' thinking. PD discusses the powers of the mind, while UTS emphasizes learning to be a better student, mainly through "metacognition." Discussions of learning and thinking strategies are all presented in these three-course subjects. These discussions appear to be similarly tackling the same topic in different angles but not necessarily an indication of increasing or levelling up of thinking skills.

14. Career and Dreams. Career paths and dreams related to it are also discussed in PD and UTS C101. PD focuses on person's and careers while UTS C101 discusses "My Dream Board," a topic that helps the student conceptualize her dream and plans of success for the future, 5 to 10 or more years from now. Topics on both PD and UTS C101 in terms of careers are tackling different aspects of the subject but do not seem to be moving from one higher level to another.

Overall, PD is more focused on topics for middle and late adolescents. UTS C101 appears to have topics and activities for discussion that fully encompasses different aspects of the self. The topics are designed to create deeper awareness, insight, and understanding of the multiple aspects of the self so that a college student will be given an avenue to develop himself fully.

15. Managing Success in College. FOS C101 is geared towards equipping students with skills on how to navigate college life successfully. The original goal of these subjects appears to be offering students various enhancements, and technical as well as essential skills to be developed. However, the observations of the course content show that there are topics repeatedly discussed or taught in all these three subjects.

\subsection{Teaching Methods and Strategies of PD, UTS C101, and FOS C101}

Teaching methods and strategies are essential components of delivering pedagogical content of lessons. It is an important facilitating factor for quality learning. The students find themselves with a good learning experience if this is executed appropriately, creative, and responsive ways. An illustration of the various methods of teaching and learning used according to the course is presented below. 
Table 1. Cross Analysis on Teaching Strategies of Personality Development, Understanding the Self, and Strategies for Academic Success in College

\begin{tabular}{|c|c|c|c|}
\hline Periods & PD & UTS C101 & FOS C101 \\
\hline Prelim & $\begin{array}{l}5 \text { interactive discussions } \\
1 \text { video clip viewing } \\
1 \text { think-pair-share }\end{array}$ & $\begin{array}{l}3 \text { guided discussion } \\
1 \text { group discussion } \\
1 \text { interactive discussion }\end{array}$ & $\begin{array}{l}1 \text { faculty-facilitated discussion } \\
4 \text { processing of learning outcomes }\end{array}$ \\
\hline Midterm & $\begin{array}{l}4 \text { interactive discussion, } 3 \text { group } \\
\text { activity } \\
4 \text { v-log }\end{array}$ & $\begin{array}{l}4 \text { guided discussion, } \\
1 \text { interactive discussion, } \\
1 \text { presentation of case study, } \\
1 \text { audio-visual activity, } \\
2 \text { lecture presentation using PPT }\end{array}$ & $\begin{array}{l}4 \text { processing of learning outcomes } \\
1 \text { group brainstorming and } \\
\text { presentation } \\
1 \text { mapping of calendar, } \\
1 \text { validating the result of } \\
\text { self-inventory on multiple } \\
\text { intelligences and learning styles } \\
1 \text { brainstorming on cheating and } \\
\text { group presentation }\end{array}$ \\
\hline Final & $\begin{array}{l}5 \text { interactive discussion } \\
1 \text { brainstorming } \\
1 \text { group activity } \\
1 \text { research } \\
1 \text { pair activity } \\
1 \text { interview } \\
\end{array}$ & $\begin{array}{l}3 \text { lecture presentation using PPT } \\
4 \text { guided discussions } \\
1 \text { mediated lecture }\end{array}$ & $\begin{array}{l}3 \text { processing of learning outcome } \\
1 \text { brainstorming }\end{array}$ \\
\hline
\end{tabular}

16. Commonly Used Teaching Strategies. For the Preliminary Period, observation of documents shows that the most commonly used teaching strategy is the use of discussion, either interactive, guided, or faculty facilitated. PD and UTSC101 utilize discussions that are interactive while FOS C101 uses faculty-facilitated discussion. These three courses seem to consider discussion as an advantageous strategy but use terms differently. In the Final Period, the typical teaching strategy given by both PD and FOSC101 is the discussion (interactive and guided, respectively). PD and FOSC101gives a group involved learning through group activity and brainstorming and pair activity. Among the three courses, FOS implicitly mentioned the use of Processing of Learning outcomes while PD has a research activity. UTS C101 was the only course in this period to use teacher-lead lectures.

17. Differences in Teaching Strategies. There seems to be much difference in the teaching strategies used in all three courses during the Midterm Period. Among the three courses, FOS C101 seems to be explicit in mentioning the processing of learning outcomes. In UTSC101, the processing of learning outcomes was embedded in guided discussions. Out of the three courses, only PD uses video clip viewing and think-pair-share activities. UTSC101 is the only one conducting group discussions during this period.

UTS and FOS utilize discussions that are interactive in nature (but differently worded; guided vs. interactive). PD has a group activity while FOS C101 has group brainstorming on presentation. Hands-on activities like mapping of a calendar and validating multiple intelligences and learning style inventories - or the use of activity-based learning assessments and its facilitating of understanding are uniquely used by FOSC101. Lecture presentations have been utilized by UTSC101, which is not seen on the other two course subjects.

The variations of the teaching strategies used by teachers, as indicated in the instructional designs of the three courses, seem to be a combination of traditional and innovative methods and strategies of teaching. The use of terms, on the other hand, is a distinct characteristic of all the identified teaching strategies employed. Some may be termed differently but seemed to have similar in strategy. As regards the level of learning acquisition, the three courses seem to have the dire need to employ well-defined strategies to hone higher-order thinking skills. The learning of soft skills needed for learners to survive tremendous adversities is evident in the courses but yet to be improved to be able to achieve desired ends of learning.

\subsection{Methods of Evaluation and Assessment of PD, UTS C101, and FOS C101}

In general, the three courses have a lot of everyday activities employed in their subjects. These various evaluations and assessments of learning methods are primarily used as both formative and summative assessments.

18. Similarity in Evaluation and Assessment Activities. A list of commonly shared evaluation and assessment activities of PD, UTS C101, and FOS C101 is presented in here.

18.1 Group Sharing Activities. One similarity noted in the evaluation and assessment of learning of the three courses is their propensity to use "group sharing activities." Group sharing activities are methods in which students who discusses topics together will learn and assess the level of learning each one has. This is a useful tool in promoting dialogue, communication and diplomatically learning to settle differences in views and 
experiences. For PD, assessment activities are think and share, discovery wheel, group sharing and group mind mapping. For UTS C101, assessment activities are mostly focused on group discussions while FOS C101 uses forum.

18.2 Group Performance. The three courses are also similar as they all use "group performance activities." These activities promote creativity, interpersonal relation-building, and synergy. PD uses skits while FOS C101 uses role-plays. PD, UTS C101, and FOS C101 all use group presentations.

18.3 Individual Activity. All three courses use individual activities that are also promoting independent learning and acquisition of skills. Some individual activities also promote self-reflection about personal plans and views in life. PD uses journal writing, vision board, using gadgets for e-learning, making e Career Plan, Article Reading, and Viewing Video Clips. UTS C101 uses written discourse, self-assessment, reflective paper, and self-analysis, while FOS C101 uses reaction papers and brain teasers. In the preliminary period, the three courses use self-expressive assessment techniques allowing students to express their thoughts and feelings in relation to the experienced activities.

18.4 Formal Tests. Two courses, PD and UTS, use summative tests as a method for evaluation and assessment of learning while FOS C101 does not.

19. Differences in Evaluation and Assessment Activities. These three courses also notably have differences in evaluation and assessment activities. FOSC101 is more focused on activities that help students understand the structure, rules and regulations, and awareness of policies of the school. FOSC101 is more focused on performance tasks that involve group participation and individual expression of opinions and ideas through forums and role-playing. PD is focused on group activities like projects and group mapping. They also have individual activities like doing concept maps, canvas, doing textbooks, journal writing, and interviewing families.

On the other hand, UTS C101 is more concentrated on allowing the student to demonstrate understanding and perception of self through an assessment activity in the classroom. Activities vary between self-assessment or written tests and reflection papers, both group and individual in nature. Only PD and UTSC101 allow assessment techniques (journal writing and reflective papers) that give freedom to students to reflect and express their opinions.

Considering the similarities in terms of the evaluation and assessment methods, it is imperative to take a better understanding of how the CLO's of each of the courses are evaluated and assessed. The alignment of evaluation and assessment must be flawlessly aligned to the parameter's teachers would want to measure, particularly on the learning outcomes.
It is easy to evaluate and assess various forms of objective tests. However, for those that require reflections, among others, subjectivity can challenge the teachers, especially when the value-belief systems of the students and the teachers seem to be incongruent from each other. For instance, the UTSC101 is a course that requires more moments of reflection, but to what extent is the learning based on reflection assessed or evaluated? The students can just write or express their thoughts and feelings, but the question on whether or not the course impacts students seem to be unclear in terms of objective assessment and evaluation. This must also be true to PD. UTSC101 and PD require authentic learning assessment forms. On the other hand, while FOS C101 evaluation and assessment methods are precise, it is also imperative to consider more improvements in the dynamics of learning evaluation and assessment. While the processing of learning outcomes is a good point of this course compared to UTSC101 and PD, the assessment and evaluation of learning necessitate clarity.

\section{Implications to Teaching and Learning}

In line with HEI's goal of increasing the quality standard of education, upgrades, and updates of curricula, syllabi, and course contents must take place. These challenges are ever-present to educators and administrators of school systems since their goal is not only to provide foundational literacy but also to ensure obtaining competencies for students.

Although we teach courses with topics that might have been touched by other subjects, the presentation of lessons must be following Bloom's taxonomy, where there is an upward and spiraling level of lessons learned. This method of increasing the level of lessons ensures that students learn vital knowledge crucial to the development of their critical minds and holistic well-being, preparing them as professionals and life-long learners. Likewise, lessons need updating and deepening to prevent boredom, unnecessary stimulation to a student, and development of critical thinking, especially when these topics will be both tackled in high school and college.

A review of the syllabic content of the PD, UTS C101, and FOS C101 showed various structural components. According to Fink (2011, p. 4), the syllabus will vary in terms of structural components or content, depending on the instructor who created them. However, similarities across courses provide information such as readings, assignments, teaching and learning activities, grading systems, and policy information. However, what seems different is the degree of information provided in terms of clarity and depth presented among these syllabi. Both PD and FOS C101 appear to be detailed, providing specific topics, activities, and teaching and learning activities. 
In contrast, UTS C101 appears to be traditional, especially in terms of activities and teaching and learning activities. The UTS C101 syllabus is lacking in specifics in terms of activities, maybe more subject to a lot of teacher interpretation and freedom in the execution of lessons. At the same time, the former two have more standardized formats creating less confusion and freedom for teachers to facilitate and guide the learning experiences of students.

It is very evident that FOS C101 employs technology-aided instruction for the longest time and that the improvements in the ways it is taught is explicit. Looking at how it is presented in the instructional design, FOS C101 can be a model course for current and future blended learning courses. However, individual and collaborative learning necessitate enhancement.

However, it cannot be denied that PD utilizes more innovative teaching methods and strategies, taking advantage of the availability of technology-based resources as well as the maximization of talents and discovery abilities of students. Additionally, PD uses both individual and group dynamics. Conducting interactive discussions, for instance, must also be clarified.

UTSC101, however, uses mostly traditional teaching methods and strategies. The teachers need to translate their creative efforts to enhance the way the course is taught to impact better learning.

With the changing characteristics and dynamics of the learners, teachers need to heighten learning motivation. With the advent of outcomes-based education, there is a necessity to improve the methods and strategies of teaching and learning.

UTS C101 must use more reflective activities to help the students understand themselves, which could give rise to understanding the self as it relates to his or her world.

Given the list of teaching methods and strategies employed in PD, UTS C101, and FOS C101, teachers are expected to revisit their teaching methods and strategies and find more meaningful strategies and maximize them for better student learning. It is also helpful for teachers to make a compendium of teaching strategies and methods of instruction with complete definition and how to do it accurately. Coining unique terms to pertain to a common strategy does not mean "better." In this way, teachers of PD, UTS C101, and FOS C101, among other courses, can rely directly upon the compendium. The universality of the methods and strategies can bring about a common understanding.

Teachers will speak in similar languages, and nobody is alienated from new terms emerging about a similar method or strategy of teaching.

\section{Conclusion and Recommendations}

While PD, UTSC101, and FOSC101 are uniquely different courses, there are particular contents where they are found similar. The pressing question now is among the three courses, "Which of them should carry those identified contents?" Another question pertaining to this is if one or more of these three courses should still need to teach similar contents, how would the lessons (or teachers) promote higher-order thinking skills as they present it to the students? Perhaps it would be necessary for department heads of representative teachers to meet together and discuss similarities in contents and discuss the way forward of teaching effectively.

In addition, the pedagogical content knowledge (PCK) of the teachers teaching the three courses must be enhanced. Teaching the three subjects with similar content may somehow prove to be challenging to students in terms of motivation to learn, seeing that they are learning similar concepts. In enhancing pedagogical content knowledge, teachers can organize knowledge from a teaching perspective designed to help students understand specific concepts according to their needs and prior knowledge, minimizing repetition.

Furthermore, teachers need to design their instructional designs to maximize their academic freedom, creativity, and innovativeness to deliver and translate better learning. Illustrating specific content of lessons is also necessary to show the uniqueness of the lessons. Developers, of course, may need to review and redesign the syllabus of the course that provides more specific information in content, teaching and learning activities, and assessment methods to ensure quality teaching and standards of good quality education are followed. Administrators and instructors may attend workshops and training sessions for syllabi creation to develop processes and procedures and acquire proper knowledge on how to create a standard syllabus. Promotion of a repository of syllabi to allow for easy review for curriculum planning, assessment, and for instructors looking for samples.

It is also advisable that a compendium of teaching methods and strategies, together with methods of assessment and evaluation of student learning, must be developed to create universality and shared understanding among teachers of PD, UTSC101, and FOSC101.

Moreover, to align these syllabi to the Outcomes-based Education (OBE) framework of the University, a revisit is needed in order to improve the instructional designs of the three subjects.

Lastly, it is also recommended that a SWOT analysis and other methods of critical assessment and evaluation of the teachers regarding their respective courses must be done to help improve more effective and efficient teaching and learning delivery. Identification of specific and transparent methods of assessments for activities requiring reflective methods is necessary to be accomplished.

\section{Acknowledgements}

The authors extend their sincerest thanks to Dr. Vicente 
K. Fabella, Dr. Miguel Carpio, Dr. Barbara Wong-Fernandez, and Dr. Auxencia Limjap for the support as well as to those who have contributed much to the completion of this project.

\section{REFERENCES}

[1] National Economic and Development Authority. Ambisyon natin 2040: A long term vision for the Philippines. Retrieved fromhttp://2040.neda.gov.ph/wp-content/uploads /2016/04/A-Long-Term-Vision-for-the-Philippines.pdf

[2] Bowen, G. A. (2009). Document analysis as a qualitative research method. Qualitative Research Journal, 9(2), 27-40. doi:10.3316/QRJ0902027/

[3] Commission on Higher Education (2013). General education curriculum: holistic understandings, intellectual and civic competencies. CHED Memorandum Order (CMO) No. 20. Republic of the Philippines. Office of the President. Retrieved from https://ched.gov.ph/cmo-20-s-2013/.

[4] Freshmen orientation seminar: course syllabus. Academic School Year 2018-2019. College of Liberal Arts, Criminology and Education. Jose Rizal University.

[5] Fink, S. B. (2011). An exploratory study on the purpose, structure, format, and use of syllabi at a midwest four-year undergraduate private university. (Publication No. 3495131) [Doctoral Dissertation, Drake University]. ProQuest Dissertations Publishing.

[6] Hess, J. \& Whittington, M. S. (2003). Developing an Effective Course Syllabus. NACTA Journal; Sep 2003; 47, 3.

[7] Lang, J. (2015). The 3 Essential Functions of your syllabus, part 2. The Chronicles of Higher Education; Washington.

[8] Nassaji, H. (2015). Qualitative and Descriptive Research: Data type versus data analysis. Language Teaching Research, Vol. 19 (2) 129-132. doi:10.1177/136216881557 2747

[9] O'Leary, Z. (2014). The essential guide to doing your research project, 2nd edition. Thousand Oaks, CA: SAGE Publications, Inc.

[10] Personality Development: Course Syllabus (2018). Academic School Year 2018-2019. Senior High School Division, Jose Rizal University.

[11] Understanding the Self: Course Syllabus (2018). Academic School Year 2018-2019. Department of Psychology. College of Liberal Arts, Criminology and Education. Jose Rizal University. 